\title{
A MASS SPECTROMETRIC STUDY OF THE STRUCTURE OF FETIDINE
}

Z. F. Ismailov and S. Yu. Yunusov

Khimiya Prirodnykh Soedinenii, Vol. 6, No. 1, p. 142, 1970

UDC $547.944 / 945+543.51$

We have studied the chemical properties of fetidine and have established its structure, I. The substance belongs to the dimeric benzyltetrahydroisoquinoline-aporphine alkaloids [1].

Under the conditions of mass spectrometry, fetidine behaves, on the one hand, as a benzyltetrahydroquinoline derivative and, on the other hand, as an aporphine derivative. As a result of instantaneous $\beta$-rupture in the benzyltetrahydroisoquinoline part of the molecule, the molecular ion is not recorded and an ion-radical with m/e 476 is formed (1.5\% of the intensity of the maximum peak, fragment a). The spectrum of the alkaloid has a peak of $\mathrm{M}^{++}$with $\mathrm{m} / \mathrm{e} 341(3 \%)$. The peak of maximum intensity corresponds to fragment $\mathrm{b}$ with $\mathrm{m} / \mathrm{e} 206$ (100\%). Fragment $\mathrm{b}$, by losing a methyl radical, gives the ion-radical $\mathrm{c}$ with $\mathrm{m} / \mathrm{e} 191(10 \%)$. The transition $\mathrm{b} \rightarrow \mathrm{c}$ is shown by the presence of a metastable peak with $m^{*}=191^{2} / 206=177$. The cleavage of the ether bridging link of fragment a leads to the splitting out of a dimethoxybenzyl radical and the appearance of ion $\mathrm{d}$ with $\mathrm{m} / \mathrm{e} 327$ (5\%). Subsequently the ion $\mathrm{d}$ with an aporphine structure, decomposes with the formation of fragment e with $\mathrm{m} / \mathrm{e} 284(3 \%)$. For $\mathrm{a} \rightarrow \mathrm{d} \mathrm{m}^{*}=327^{2} / 476=224$.

Thus, the features of the mass spectrometric fragmentation of fetidine confirm the structure I proposed for it.

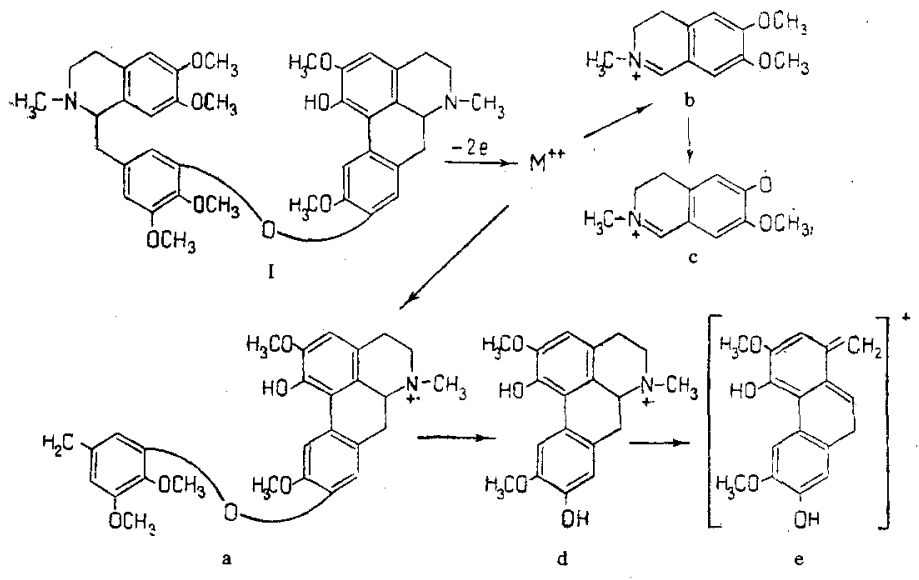

\section{REFERENCE}

1. Z. F'. Ismailov and S. Yu. Yunusov, KhPS [Chemistry of Natural Compounds], 2, 43, 1966.

19 September 1969

Institute of the Chemistry of Plant Substances, AS UzSSR 